\title{
Hunting habits of lions
}

Sarah C. P. Williams

Science Writer

As the sun sets on the African Savannah, lionesses can be spotted prowling the open land, hunting and making kills, often as a group. Males are more often lounging around during this time, leading some observers to the assumption that they're lazy, poor hunters, and take advantage of the females' kills as their food source, says Scott Loarie, of the Carnegie Institution for Science. However, when Loarie heard repeated anecdotes of naturalists coming upon males successfully making kills in more hidden areas, he

began to suspect that they're not such bad hunters after all, but might have a different strategy than females.

To probe how, where, and when male and female lions hunt, Loarie and his collaborators combined two technologies. They first fastened GPS collars onto lions at South Africa's Kruger National Park, allowing them to track where each lion wandered throughout the day and where and when it hunted. Then, they flew an airplane over the park and used Light Detection and

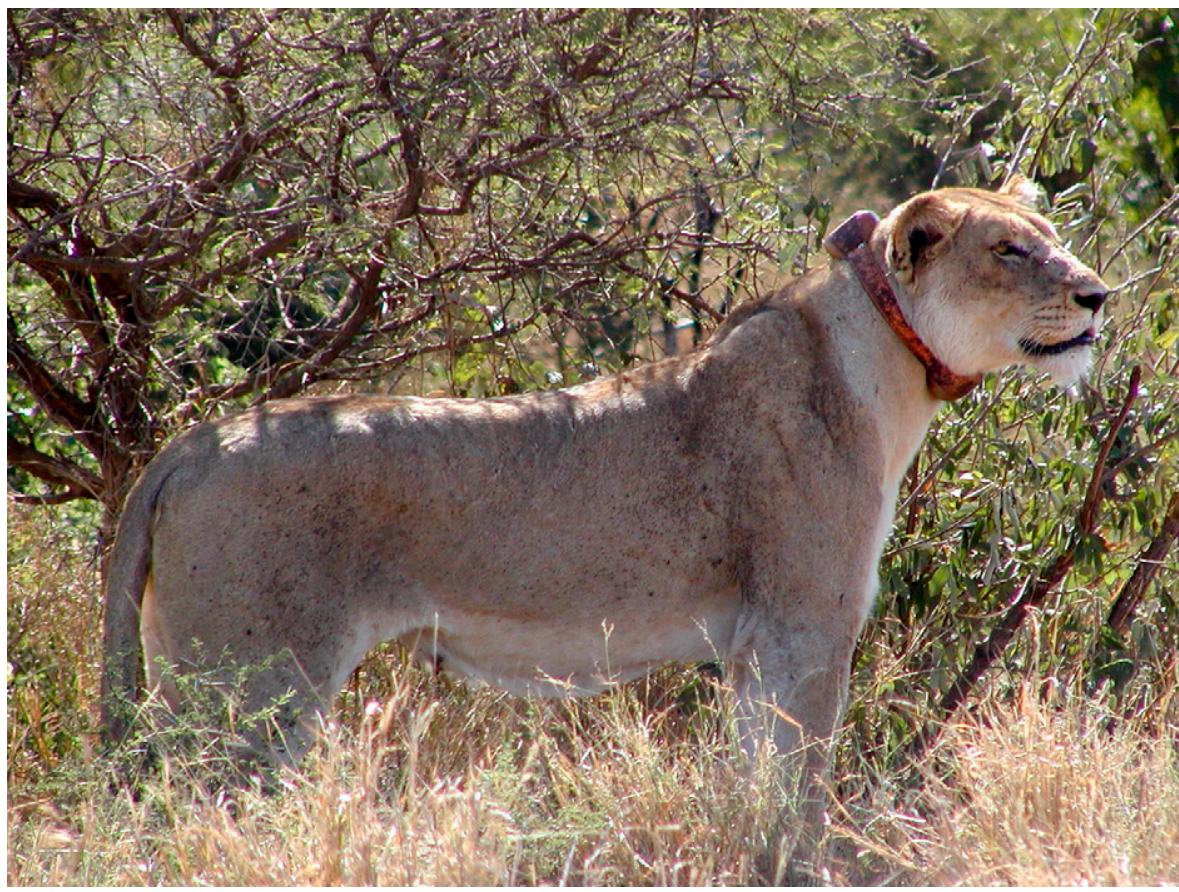

A GPS-collared lioness in South Africa's Kruger National Park surveys the landscape. Image courtesy of Craig Tambling.
Ranging (LiDAR), a form of radar, to get high-resolution imagery of all of the vegetation patterns in the area. With LiDAR, the scientists could not only see the upper level of the forest's canopy, like previous satellite images had provided, but each plant layer beneath. It offered the most detailed images yet of the structure of the Park's flora.

By combining the two data sets for the first time, Loarie's team could draw conclusions about how male and female lions use different types of landscapes for hunts.

"Females are hunting and lounging in the same areas," Loarie explains. "The females team up to hunt in groups in these open areas," he says. "While the males lounge in more open areas and then go to denser parts of the landscape to hunt."

This research not only begins to explain how male and female lions' hunting strategies differ but also provides information on how changes to vegetation could impact the predator-prey balance in Africa.

"We've just done the very first step of saying there's this causal relationship between lion hunting behavior and vegetation," Loarie says. "But what does that tell us ultimately about ways we can manage these parks to ensure that this menagerie of biodiversity can continue to exist?" he says.

Loarie plans to apply the combined LiDAR-GPS tag technique to other animals to further explore the relationship between animal predator-prey behavior and vegetation. His team is currently analyzing data on the sable antelope.

"Once ecologists become more comfortable with these technologies, we can apply them more and more to fields like animal behavior which have mostly been done in the past with naturalists in the field with a pad of paper and a pen," says Loarie. 